\title{
A Study on the First Public Gymnasium in China - Shanghai YMCA Sichuan Rd Club
}

\author{
Liu Pinghao and Zhu Wenyi
}

\begin{abstract}
Shanghai YMCA Sichuan Rd Club, built in 1907, was the first public gymnasium in China. Belonged to Church, the YMCA was not considered to be a sport building. However, China YMCA buildings, started with Sichuan Rd Club, made a great contribution to the development of China's fitness culture and physical education. In this Club, China's modern physical culture started and physical education was brought to the public. With the swimming pool added to the original gymnasium, the "Gymnasium + Swimming Pool" YMCA prototype first appeared in China, which set the standards of gymnasium architecture for the YMCA followers in China and then other public stadiums.
\end{abstract}

Index Terms-Fitness culture, gymnasium architecture, physical training, Shanghai YMCA Sichuan rd club.

\section{INTRODUCTION}

Public Gymnasium is a public place where people of all ages get exercise and physical training, which can be dated back to Ancient Greece. Modern Gymnasium was created in Germany in form of "Turnen" and soon spread all over the world [1]. Unlike Chinese traditional physical culture (Zen, Qigong and so on), Chinese public fitness culture was completely imported after the First Opium War, 1840. In this period, western churches as well as YMCAs made a great contribution to spreading the public gymnasium idea, fitness culture and then sport movement.

Belonged to Church, the YMCA (Young Men's Christian Association) focuses on religious education to youth in the way of courses, salons and lectures. As the advocates of Muscular Christianity made a combination of physical and moral health in 1860s [1], ancient Greek training methods, "Turnen" and other kinds of exercise and physical training had been introduced to YMCA as physical education. YMCAs gradually became the centers of youth exercise, in which many modern sports were born, such as basketball, handball, etc.

Shanghai YMCA Sichuan Rd Club (Fig. 1), built in 1907', was not the first YMCA in China (The First YMCA in China

Manuscript received August 20, 2015; revised December 20, 2015

The authors are with the School of Architecture, Tsinghua University, Beijing 100084 P.R.China (e-mail: richardlph2005@126.com, zwy_80@126.com).

${ }^{1}$ Shanghai YMCA was established in January, 1900. The origin club was in South Suzhou Rd 17, and then moved to Nanjing Rd 10 in October, 1900. As member increased, in 1903 there was not enough space and then in July, Shanghai YMCA moved to Beijing Rd 15B. In 1905, committee proposed to build a new YMCA building instead of rent other buildings. With enough donation, in 1907, the new Sichuan Club was built with the China first gymnasium and a lecture hall. In 1909, Boy's building was planned and completed in 1915 with a swimming pool. This building was being used till 1931 when a new YMCA club was built in Baxian Qiao District, which was Tianjin YMCA in 1896). However, it was the first purpose-built YMCA building with gymnasium in China. As the First Public Gymnasium, Sichuan Rd Club Building was named the forth batch of Shanghai Outstanding Historical Buildings (Fig. 2) in 2005. ${ }^{2}$

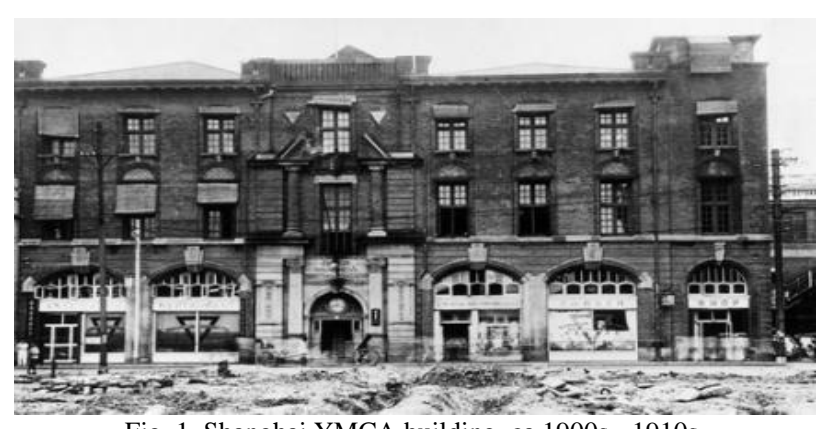

Fig. 1. Shanghai YMCA building, ca 1900s - 1910s.

("Shanghai YMCA building", photo of collection, records of YMCA international work in China, Kautz family YMCA archives, University of Minnesota libraries).

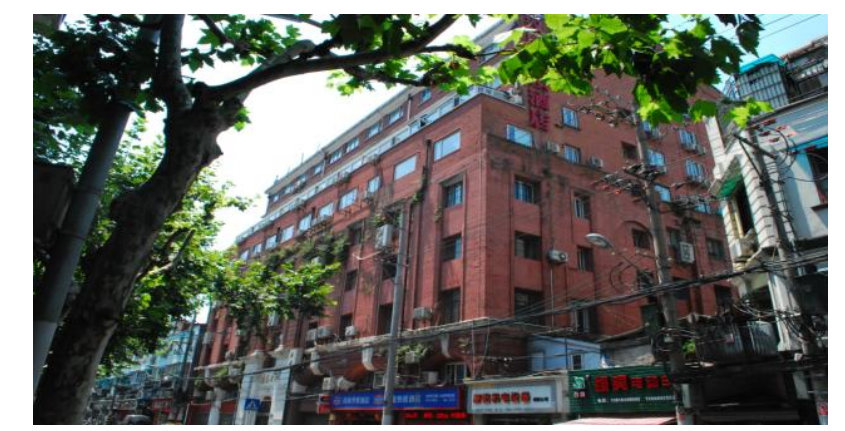

Fig. 2. Shanghai Puguang high school (Shanghai YMCA building) ca 2015.8 (photographed by author).

\section{ORIGIN OF ChINA’s MOdERn FITNESS CULtURE}

Since the First Opium War, more and more western culture had been imported into China. In the last decades of the 20th century, plenty of sports, like swimming and the basketball, had been brought into Guangzhou, Tianjin, Shanghai and other big cities at that time. Unlike the sports mentioned, fitness culture, which was a part of western physical education and was attached to school gymnasiums and YMCAs, was imported into China by YMCAs. As a result,

became the later administration center of Shanghai YMCA. The Sichuan Club then only focused on education.

${ }^{2}$ The building is now used as Puguang Middle School since Pudong Middle School's predecessor, RiXiao (Day School) started from 1901. In 1992, as tear and wear of the previous building, the boy's building was reconstructed from a 4-floor wooden-and-brick building into 5-floor reinforced concrete building. In the following year, the main building was also reconstructed and reinforced while the appearance of the main building was preserved. An additional floor was stuffed into the previous building and additional 4 floors was built on the roof of the previous building. 
the founding of Shanghai YMCA Sichuan Rd Club marked the origin of modern fitness culture in China.

In 1919, with the lead of Dr. M. T. Exner, a modern exercise system was built. Dr. Exner was sent by US YMCA to China for the Physical Education Course in China. He picked 20 young people and began to train them physically (Figure 3). Then, as Shanghai YMCA gymnasium was open, they had a successful show, which presented the potential and hope of Chinese nation in Physical and Sport [2]

With the popularity and community influence of Rixiao (Day School) [3] and Yexiao (Night School) [3], which were managed by Shanghai YMCA and supported by Middle and Upper Class of Shanghai society, Gymnasium in Sichuan Rd Club was soon accepted and furthermore loved by more Middle Class, though fitness culture and physical training came from Western Culture. The gymnasium became the most attractive and popular place of Shanghai YMCA at that time.

Nevertheless, the popularity of gymnasium in Shanghai YMCA indicated the rapid spread of fitness culture in Shanghai society. Following this fitness trend and the call of Muscular Christianity, Shanghai YMCA built the Boy's Building adjacent to the Sichuan Rd Club on the west, which included an indoor Ping Pong Room, as well as an indoor swimming pool which was the first indoor swimming pool in Shanghai (Fig. 4-Fig. 5). Although it was not the first in China $^{3}$, the indoor swimming pool was remarkable in physical history as it extended the gymnasium space and became an important extension of physical training of Shanghai YMCA.

The prototype of YMCA with swimming pool first appeared in Chicago YMCA in 1885. The indoor pool was first used for bathing, playing and competitive swimming, which soon became popular. As a result, there were 17 YMCAs with swimming pools by 1895 . It became a standard prototype for the later YMCAs [4]. While in China, with the founding of the indoor swimming pool in Boy's Building of Shanghai YMCA, the "YMCA with Pool" prototype was brought in which then became a great success. Unlike individual natatorium, the indoor swimming pool in YMCA could benefit from the gymnasium and promote swimming culture better as well as increase the variety of the physical training in YMCA. To be concluded, the indoor swimming pool in Shanghai YMCA was a great successful approach of physical training system and a spatial evolution of fitness culture in China.

As more and more people came to Sichuan Rd Club for the gym and the swimming pool (Fig. 6), western fitness culture and physical training had been integrated into the life of Shanghai Upper and Middle Class. Although, it is unable to calculate the exact number of people who had attended the physical training of Shanghai YMCA or to quantify the benefit of the YMCA gymnasium and swimming pool to the health of Chinese people, there's no doubt that YMCAs acted as the "preacher" of the fitness culture and physical training, and among them, Shanghai YMCA Sichuan Rd Club was the pioneer (Table II).

${ }^{3}$ The first indoor swimming pool was a natatorium in Shamian, Guangzhou, which was around $22.5 \mathrm{~m}$ long. Now, it is still being used and is one of the top-10 swimming pools in Guangzhou.

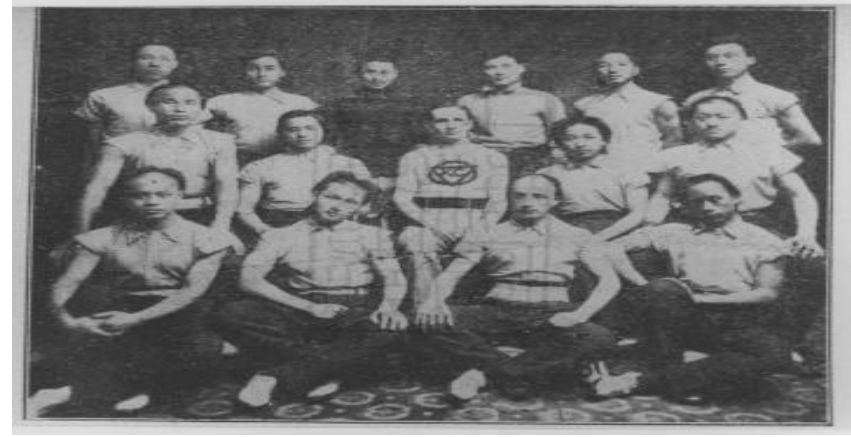

Fig. 3. The first gymnasium class of Shanghai YMCA. (Shanghai memory (http://memory.library.sh.cn/node/31454, 2015.08).

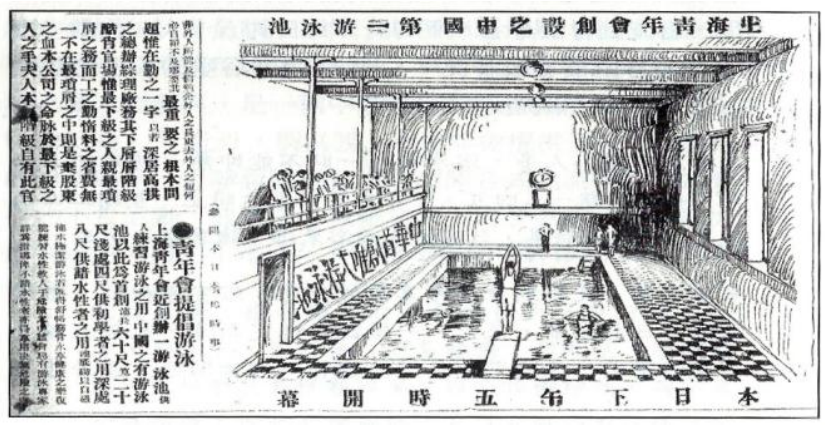

Fig. 4. News report of the opening of indoor swimming pool in Shanghai YMCA Sichuan rd club boy's building [5]

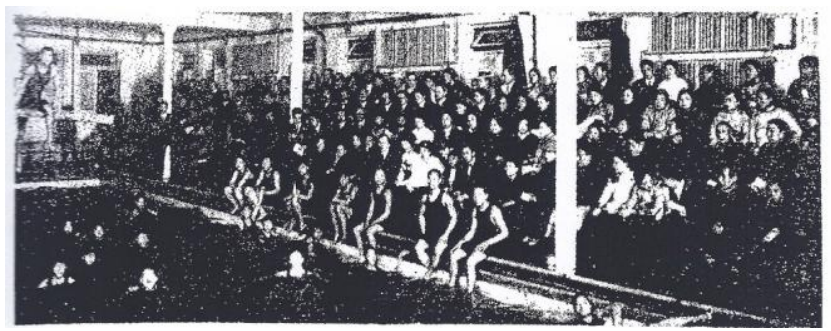

Fig. 5. The indoor swimming pool of Shanghai YMCA [2]. This poster was a false news not only as this was not the First indoor swimming pool in China, but also the real swimming pool was only $3.5 \mathrm{~m}$ in clear height and there were no stands. From the photo, we can find that, unlike the space shown in the poster, the pool was only 1 -floor space and there were several pillars on the sides of the swimming tank. The space of this indoor pool was narrow comparing with those of today. However, it was no doubt the first indoor swimming pool within China YMCA.

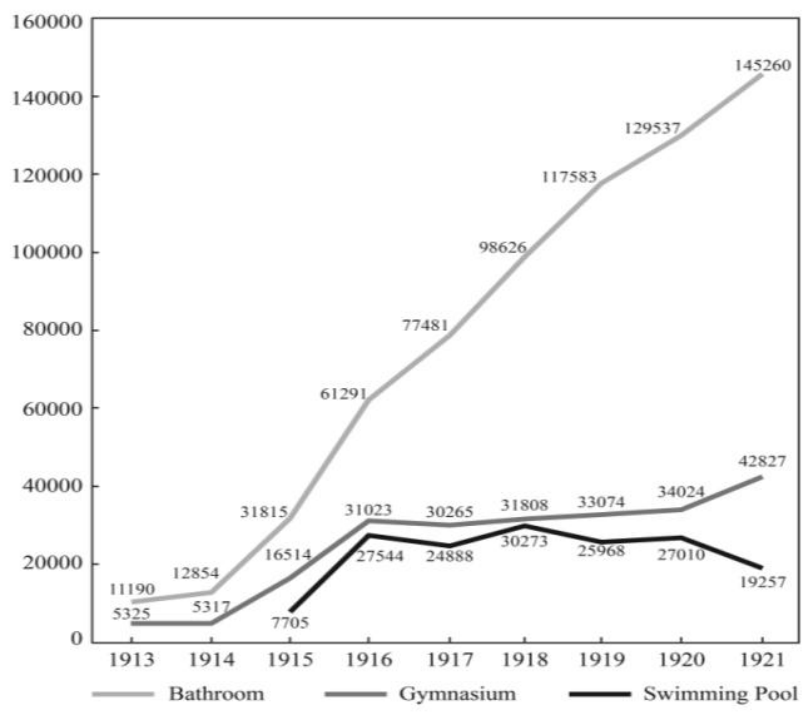

Fig. 6. Use of the Sport Facilities in Shanghai YMCA Sichuan Rd Club (Data is from Annual Report of CYMCA of Shanghai, 1913-1921) As the swimming pool started in 1915, the use of the gymnasium and bathroom increased obviously which meant the great success of the new YMCA mode. 


\section{The First ChInA GyMnASIUM ARCHITECTURE}

As the first gymnasium of China, Shanghai YMCA Sichuan Rd Club was built in 2 phases: Phase 1 was the main building on the east side and Phase 2 was the Boy's Building on the west side. (Fig. 7) The whole YMCA club was not a total gymnasium full of training facilities, but a public education institute, inside which the gymnasium was a space for physical education. Besides, there were classrooms, a lecture hall, and dormitories in this YMCA building.

The main building of this YMCA club (1907) in Phase 1 is a total neo-classical building designed by Algar \& Beesley, the only architecture design institute which was experienced in YMCA building design at that time [6]. Restricted by the budget, this 3-floor building did not have a symmetrical layout of three longitudinal zones as other American YMCA buildings did in neo-classical style. The main façade material was exposed bricks painted red, while stones were only used around the entrance in order to reduce budget. The façade of the building was symmetrical if the north span was excluded. The façade of the ground floor had 5 arches in bigger scale with keystones, while that of the 2nd and 3rd floors had black steel windows with 3-4 layers of moldings to strengthen the lateral zones. What's more, the number of spans of the ground floor differed from that of the 2-3 floor in purpose. The idea of a roof garden had been included in the previous proposal but was cancelled to reduce the budget. The main entrance was decorated with the broken white triangle pediment and square IONICOs for attraction. (Fig. 8-9)

The Boy's Building (1915) in Phase 2 had similar style with the Main Building, with more inner space and simpler façade. It was designed by an officer of Architecture Institute of China YMCA and revised by Shattuck \& Hussey (Shattuck \& Hussey was the designer of many American YCMAs as well as Tianjin YMCA (1914), China). With the debt burden of main building, the style of the Boy's Building was more practical. The 5-floor façade included 5 vertical spans, with less decoration and windows frames. However, the main building was harmonies and elegant with a layout of three longitudinal zones remained (Fig. 10- Fig. 11).

Shanghai YMCA Sichuan Club had a lot in common with the New York YMCA (1869), the first purpose-built YMCA building in the world. Although in different sizes, they all had Neoclassicism style and the symmetrical façade. The stones used in the façade increased the solemnity of the building, although the main building and boy's building of Shanghai YMCA only used stones around the entrance because of budget (Table I).

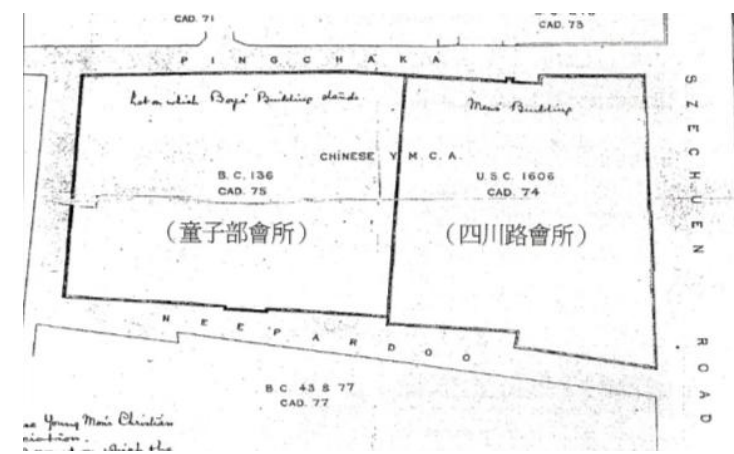

Fig. 7. The location of boy's building and main building of Shanghai YMCA Sichuan rd club [3].

The function of YMCA clubs included 2 parts: Intellectual
Education and Physical Education. (Fig. 12) Intellectual Education included the Rixiao and Yexiao mentioned above, took place in the auditorium hall, the reading room, the lecture room, class rooms, etc. Physical Education included the bath room, the billiards room, the ping pang room, the swimming pool, basketball fields as well as the gymnasium. In Shanghai YMCA Sichuan Rd club, most parts of the Main Building is for the intellectual education except for the gymnasium. However, as physical education became more and more popular since the first gymnasium, the Boy's Building included more space for physical education, including the swimming pool, the ping pong room, etc.

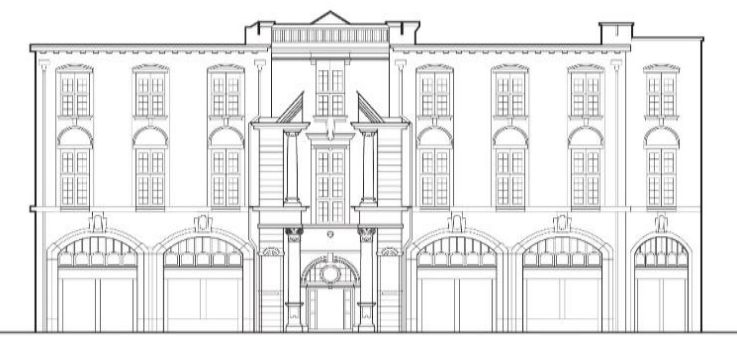

Fig. 8. The main façade of main building of Shanghai YMCA Sichuan Rd club (drawn by author).

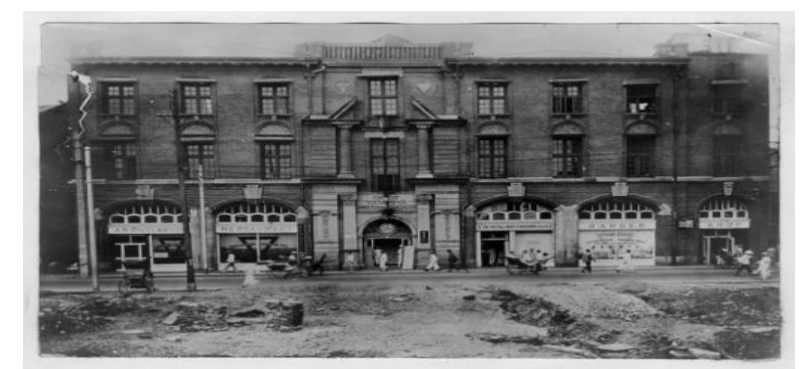

Fig. 9. Scechuen (Sichuan) Road, ca. 1938

(Scechuen Road, ca. 1938, Photo of Collection, Records of YMCA International Work in China, Kautz Family YMCA Archives, University of Minnesota Libraries.)

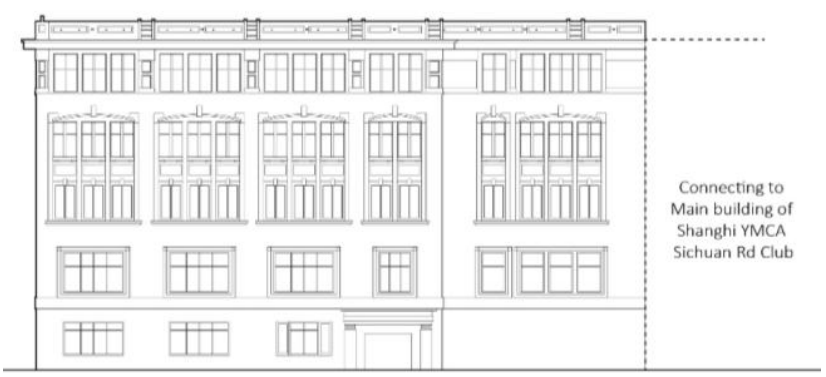

Fig. 10. South façade of boy's building of Shanghai YMCA Sichuan rd club (drawn by author).

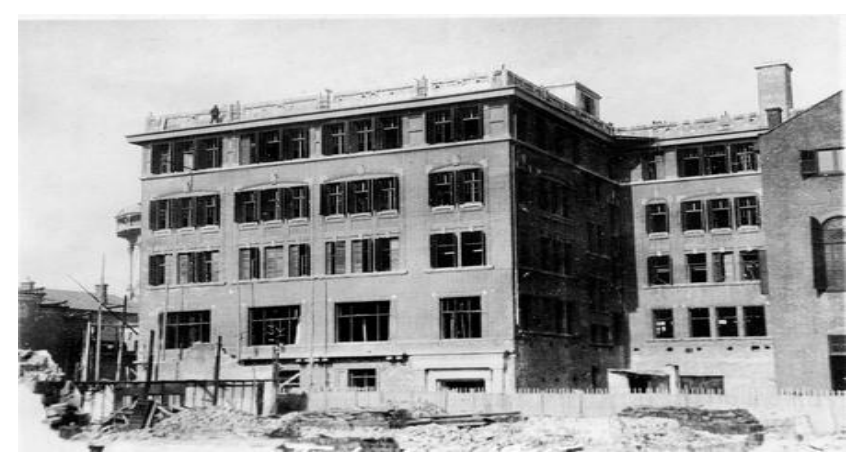

Fig. 11. Boys Building - Shanghai, China

(Boys building - Shanghai, China, photo of collection, Records of YMCA international work in China, Kautz Family YMCA Archives, University of Minnesota Libraries.) 
TABLE I: THE COMPARE OF 3 YMCAS

\begin{tabular}{|c|c|c|c|}
\hline Channels & $\begin{array}{l}\text { New York } \\
\text { YMCA }\end{array}$ & $\begin{array}{l}\text { Shanghai YMCA } \\
\text { Main building }\end{array}$ & $\begin{array}{l}\text { Shanghai YMCA } \\
\text { Boy's Building }\end{array}$ \\
\hline Built time & 1869 & 1907 & 1915 \\
\hline Architect & $\begin{array}{l}\text { Shattuck \& } \\
\text { Hussey }\end{array}$ & Algar \& Beesley & $\begin{array}{l}\text { Authur Adamson } \\
\text { Shattuck \& Hussey }\end{array}$ \\
\hline Style & $\begin{array}{l}\text { Neoclassicism } \\
\text { Three } \\
\text { longitudinal } \\
\text { zones }\end{array}$ & $\begin{array}{l}\text { Neoclassicism } \\
\text { Two longitudinal } \\
\text { zones }\end{array}$ & $\begin{array}{l}\text { Neoclassicism } \\
\text { Three longitudinal } \\
\text { zones }\end{array}$ \\
\hline Floor & $\begin{array}{l}5 \\
\text { with basement }\end{array}$ & $\begin{array}{l}3 \\
\text { no basement }\end{array}$ & $\begin{array}{l}5 \\
\text { no basement }\end{array}$ \\
\hline $\begin{array}{l}\text { Physical } \\
\text { Training }\end{array}$ & $\begin{array}{l}\text { Gymnasium in } \\
\text { basement }\end{array}$ & Small gymnasium & $\begin{array}{l}\text { Indoor swimming } \\
\text { pool, Ping Pong ball } \\
\text { field, etc. }\end{array}$ \\
\hline $\begin{array}{l}\text { Other } \\
\text { function }\end{array}$ & $\begin{array}{l}\text { A Lecture Hall, } \\
\text { Classrooms, a } \\
\text { Library }\end{array}$ & $\begin{array}{l}\text { A lecture hall, } \\
\text { Classrooms }\end{array}$ & $\begin{array}{l}\text { Classrooms, } \\
\text { Dormitories }\end{array}$ \\
\hline
\end{tabular}

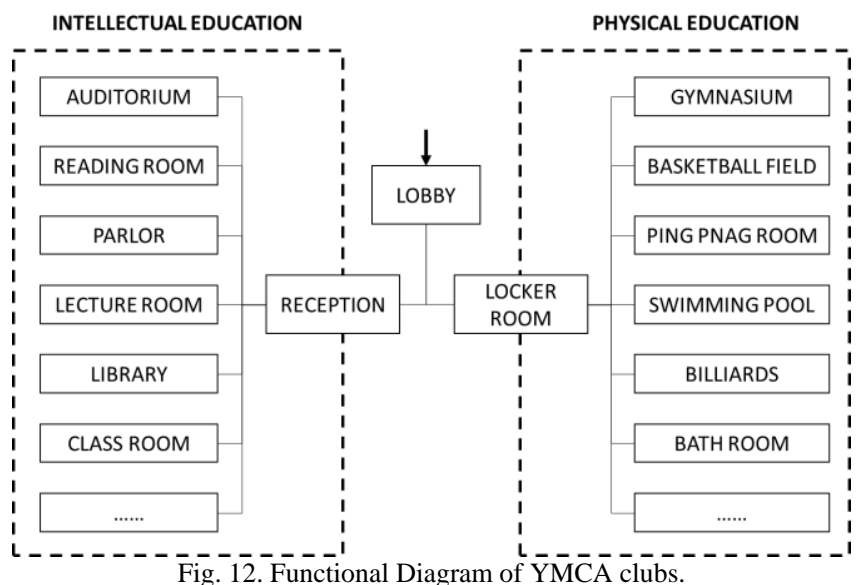

(drawn by author).

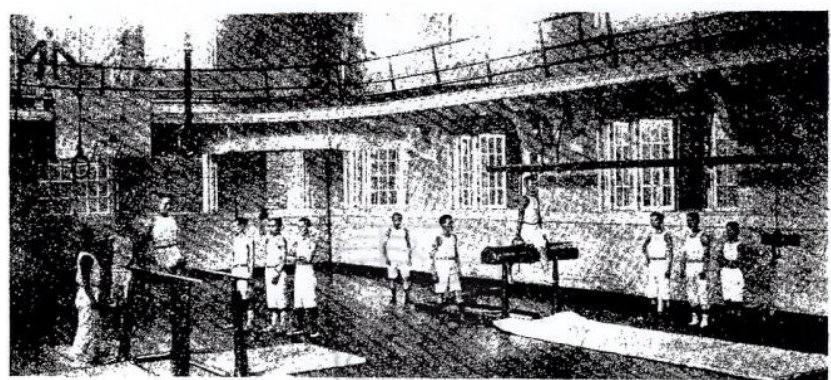

Fig. 13. The gymnasium of Guangzhou YMCA [2].

Young people were training in Turnen system with several classical facilities, like parallel bars, single bars and pommel horses. Besides for the physical training, the basket board hanging on the edge of the second-floor jogging track indicated that this gymnasium field was also used as a basketball field.

In terms of the gymnasium space in the Main Building, because there were not enough records on this space, we cannot image the exact space of this first gymnasium of China. But through the photo record (Fig. 13) of the Guangzhou YMCA gymnasium (1914) as the reference, we can find out the physical training system of the Shanghai YMCA gymnasium, as the Guangzhou YMCA was no doubt the Shanghai YMCA's follower on the training system. In this photo, the training facilities in Guangzhou YMCA gymnasium included parallel bars, single bars and pommel horses, which were almost the same as that in New York YMCA (Fig. 14). This indicated that the training system in China YMCAs was originated from German Turnen system
(1811) [4] and American Turnverein (1820s). This system has over 200 years' history and even now, in high schools PE classes, we are still using the similar system with almost the same facilities. Besides, in another photo of Shanghai YMCA gymnasium with unknown time (Fig. 15), we can see the class of Kong Fu, which was in traditional Chinese physical training system. It indicated the contribution of the Shanghai YMCA in combining the western Turnen system with the Chinese tradition.

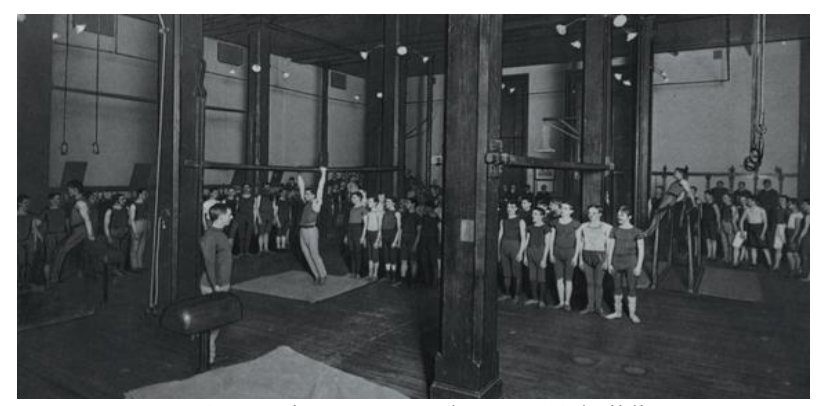

Fig. 14. Gymnasium, New York’s YMCA building [4].

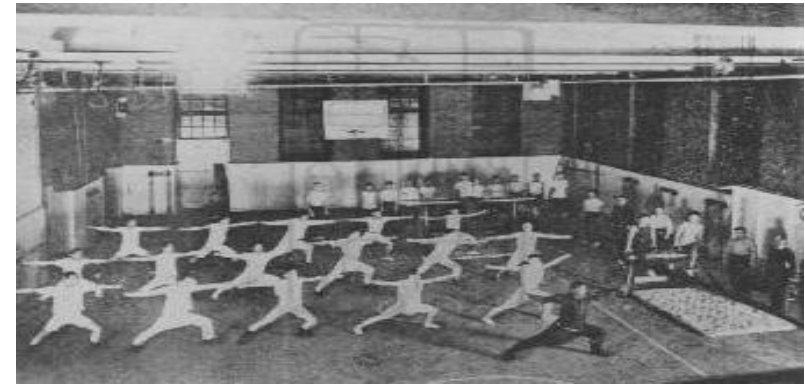

Fig. 15. The Kong Fu class of Shanghai YMCA.

(Shanghai Memory (http: / /memory. library. sh. cn / node / 31455, 2015.08)) Young people were training Kong Fu in the gymnasium of Shanghai YMCA. But as we do not have more information of this photo, we could not identify whether it was in Sichuan YMCA club or not. But at least, it proved that the training system of the gymnasium in Shanghai YMCA was not only Turnen, but also Kong Fu and other Chinese training systems.

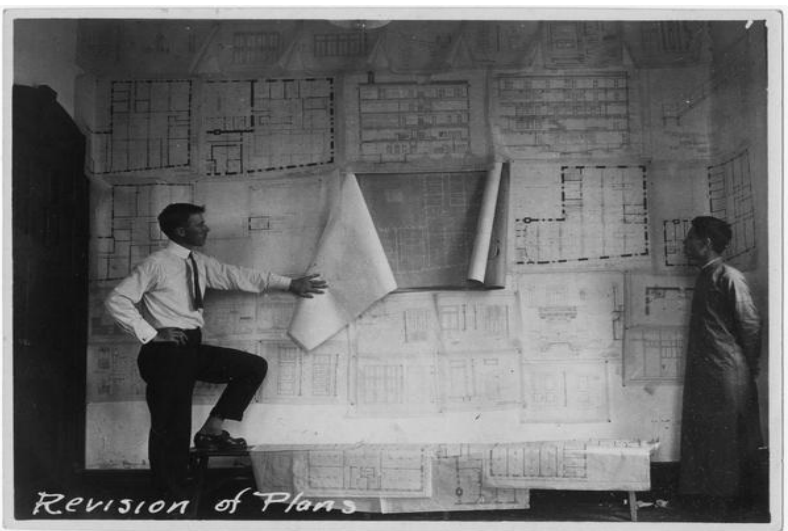

Fig. 16. Shanghai boys' building - Revision of plans.

(Shanghai Boys' Building - Revision of Plans, Photo of Collection, Records of YMCA International Work in China, Kautz Family YMCA Archives, University of Minnesota Libraries.)

Through the photo of the revision, we can find the plan of swimming pool on the first row of the second line on the left and the section on the first row of the 4 th line on the left. 
With a photo of a design revision of Boy's Building (Fig. 16), we can find the plan and section of the swimming pool inside. As another highlight of Shanghai YMCA Sichuan Rd Club, the pool was 60 feet $(18.3 \mathrm{~m})$ in length and 20 feet $(6 \mathrm{~m})$ in width and the depth of the pool varied from 4 feet to 8 feet (1.2m-2.4m). Comparing with the indoor swimming pool of Chicago Central YMCA (1885), one of the world's biggest YMCA at that time $(71 \times 22$ feet, $21.6 \times 6.7 \mathrm{~m})$ (Fig. 17), the swimming tank of Sichuan Rd club was among the high-level of international YMCA swimming pools.

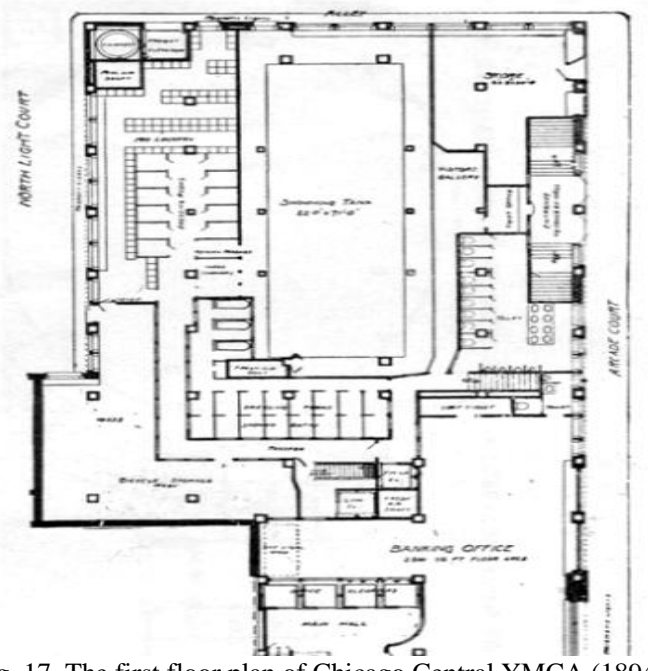

Fig. 17. The first floor plan of Chicago Central YMCA (1894) [4] The swimming pool part was in the middle of the south side.

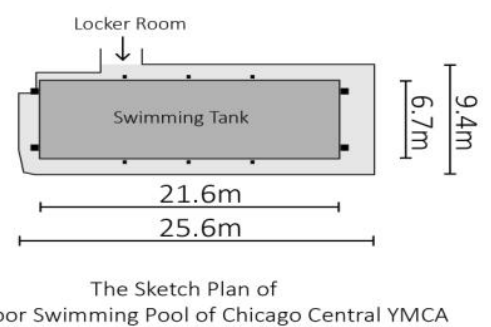

the Indoor Swimming Pool of Chicago Central YMCA

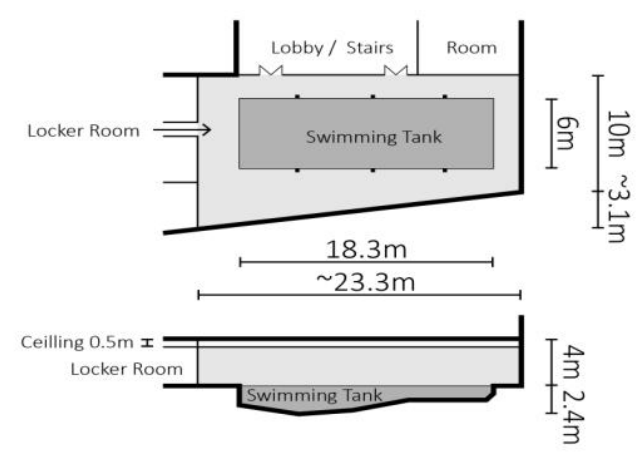

The Sketch Plan and Section of

the Indoor Swimming Pool of Shanghai YMCA Sichuan Rd Club

Fig. 18. The compare of the swimming pools of Shanghai YMCA Sichuan rd club and Chicago central YMCA (drawn by author).

The room for the swimming pool was a right trapezoid in plan, which was $270 \mathrm{~m}^{2}$. With the width of $23 \mathrm{~m}$, the short side was $10 \mathrm{~m}$ while the long side was $13 \mathrm{~m}$. The room was only 1 -floor with $3.5 \mathrm{~m}$ celling height. The column grid was $6 \mathrm{~m} \times 6 \mathrm{~m}$ and as a result, there were still 3 pairs of pillars on the long side of the pool. Comparing with the room of pool in Chicago Central YMCA $\left(234 \mathrm{~m}^{2}\right)$, although with a smaller swimming tank, the room space of Shanghai YMCA swimming pool was contrarily larger (Fig. 17- Fig. 19) which means the better space quality.

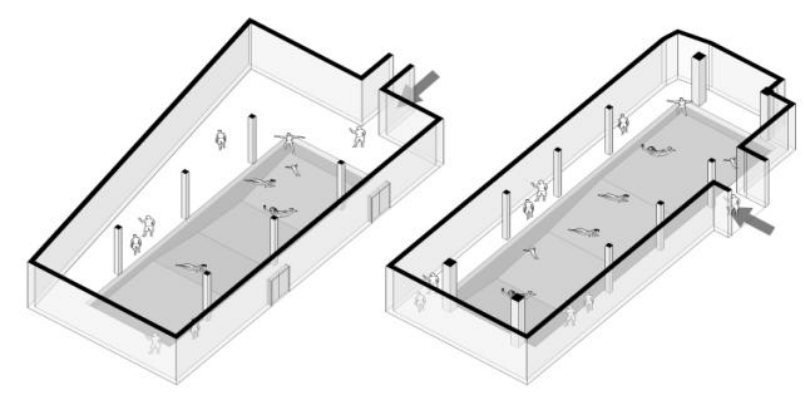

Fig. 19. The digital model compare of the swimming pools of Shanghai YMCA Sichuan Rd Club (left) and Chicago Central YMCA (right) (drawn by author).

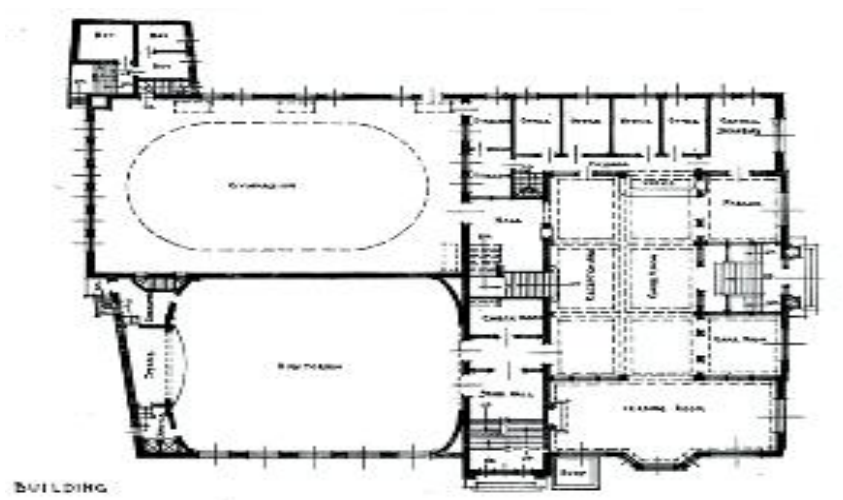

Fig. 20. First-floor plan, Tientsin, China, YMCA Building, by Shattuck and

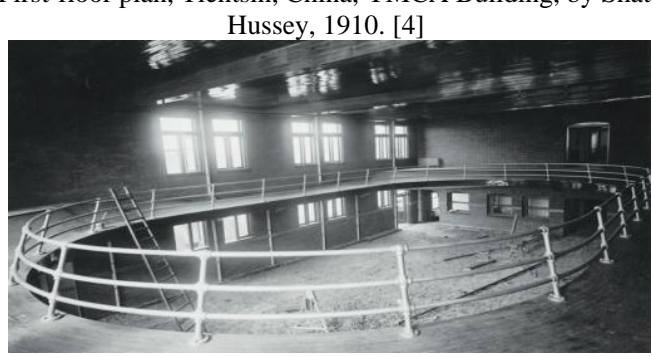

Fig. 21. Y.M.C.A. Building, Tientsin, China - 1914.

(Y.M.C.A. building, Tientsin, China - 1914, photo of collection, records of YMCA international work in China, Kautz Family YMCA Archives, University of Minnesota libraries).

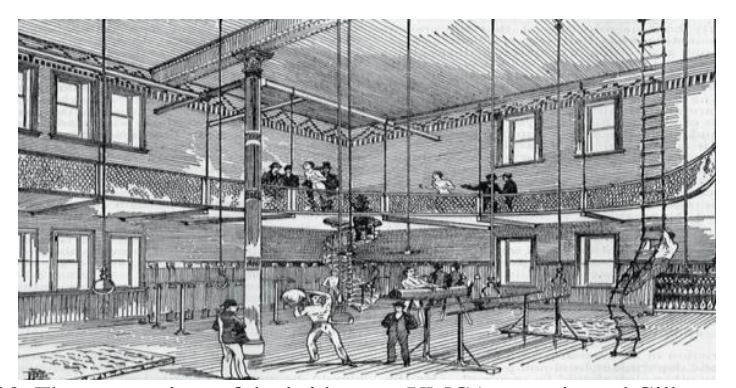

Fig. 22. The gymnasium of the bridgeport YMCA, at main and Gilbert streets, bridgeport, connecticut, 1892 [4].

\section{PRototype OF MOdern China SPORT ARCHITECTURE}

In terms to architecture field, YMCA buildings are not regarded as sport buildings, but religious or educational buildings. The main reason is that physical education was only part of the YMCA activities. In China, YMCA was more 
like a School or an Educational Institute providing programs like Science, Religious Education, etc. However, as the carrier of modern sport, YMCA had made a great contribution to the spread of sport movement since the beginning of $20^{\text {th }}$ century in China. People got to know and love physical training as well as basketball, ping pong through the participation to the YMCA. Furthermore, YMCA buildings were important references for the modern sport architectures, especially the gymnasiums.

As the first purpose-built YMCA club with gymnasium in China, Shanghai YMCA Sichuan Rd Club was no doubt the pioneer of China Public Gymnasiums, which set the standards for the gymnasium buildings. Tianjin YMCA Club (1914) (Fig. 20-21), Guangzhou YMCA Club (1914) (Fig. 13) and Hong Kong YMCA Club (1918) were the examples of the following purpose-built YMCAs in China. All the 3 YMCAs above inherited the Turnen system which Shanghai YMCA imported as training methods. Furthermore, they imported the specific YMCA gymnasium type created in Boston (1873) and Bridgeport (1892) YMCA gymnasiums ${ }^{4}$, which contained a big indoor space 2-floor high, with an indoor playground in the center and a jogging track around the playground at the height of the $2^{\text {nd }}$ floor (Fig. 22).

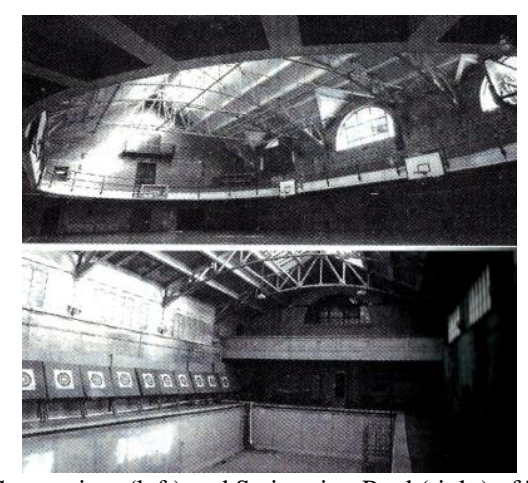

Fig. 23. The Gymnasium (left) and Swimming Pool (right) of Tsinghua West Stadium [7].

The 1916-1921 part of Tsinghua West Stadium was its first phase, which contained a gymnasium, a swimming pool and several other support facilities, much like the physical education part of a YMCA. Its gymnasium was $563 \mathrm{~m}^{2}$, with the second-floor jogging track and several basket boards. Now the jogging track is use as stands. The swimming pool was $280 \mathrm{~m}^{2}$, with a swimming tank $(18.8 \mathrm{~m} * 8.2 \mathrm{~m}) 1.13 \mathrm{~m}-$ $2.67 \mathrm{~m}$ depth.

Besides, Shanghai YMCA Sichuan Rd Club learned from the American "gymnasium + swimming pool" prototype and imported it into China, which greatly influenced the YMCA buildings all over China in the following years. Hong Kong YMCA and Guangzhou YMCA successfully followed this prototype which both included gymnasiums and swimming

${ }^{4}$ There were 2 main reasons of why Shanghai YMCA did not use this type of gymnasium. First was the budget. The donations were so limited that they could not afford such type of gymnasium with large indoor space. Second was the fitness culture. Before 1907, the main activities of Shanghai YMCA were the Rixiao and Yexiao while physical education was seldom been mentioned. There was not enough basis of western fitness culture in Shanghai that time. So it would be a great risk if such big gymnasium was built. Besides, in 1905, the Committee of the Martys' Memorial Hall met the Shanghai YMCA Committee, and hoped to add a hall to the future Sichuan Rd Club which could contain 700 people. In return, they would donate 9000 Yuan. As a Result, the big gymnasium of the former design was replaced by a big lecture hall. pools. They all became the first batch of Sport Buildings, and made great contributions to the sport movement. (Table II)

The influence was not only within the YMCA, but also to the typical sport architectures, like stadiums, especially in universities in China. Tsinghua West Stadium, which was the first stadium within China universities, was a follower of "Gymnasium + Swimming pool" prototype. What's more, the gymnasium was in YMCA style, the same with Hong Kong and Guangzhou YMCAs. (Fig. 23-24) Shanghai YMCA Sichuan Rd Club created the Chinese style of YMCA Architecture, and greatly influenced the sport architectures since then.

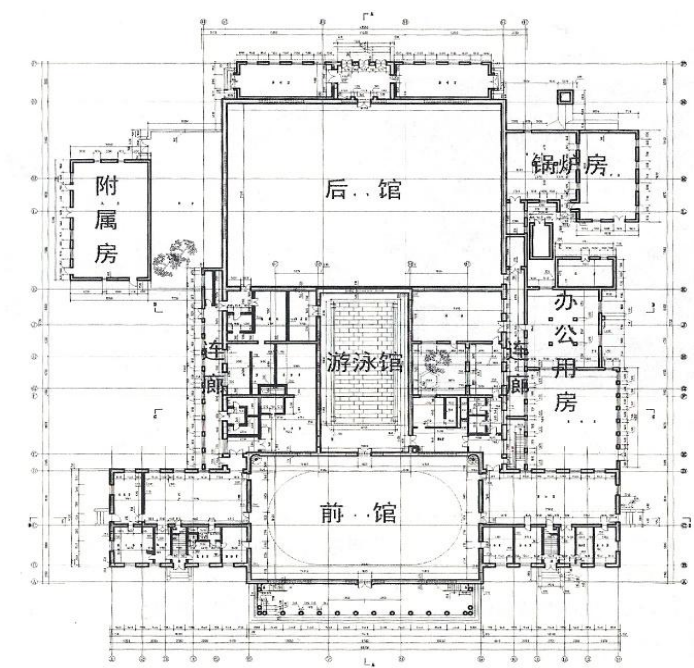

Fig. 24. First Plan of Tsinghua West Stadium (2007.4) [7] The gymnasium was in the middle of the south side. The swimming pool was in the middle of the whole building. The other part of this stadium was built in the following phases.

TABLE II: LIST OF PURPOSE-BUILT BUILDINGS OF YMCA IN CHINA 1896-1935

(DATA IS FROM FIFTY-ANNIVERSARIES OF YMCA IN CHINA, 1935)

THE BOLD MEANS THE BUILDING INCLUDED GYMNASIUM

\begin{tabular}{|c|c|c|}
\hline Period & Built Year & YMCA Buildings \\
\hline Founding & 1896 & Tianjin YMCA(1895) in Hai Rd \\
\hline Growing & $\begin{array}{l}1907 \\
1912\end{array}$ & $\begin{array}{l}\text { Shanghai YMCA(1900) in Sichuan Rd } \\
\text { Chengdu YMCA }(1910)\end{array}$ \\
\hline Developing & $\begin{array}{l}1913 \\
1914 \\
1915 \\
1916 \\
1917\end{array}$ & $\begin{array}{l}\text { Beijing YMCA(1907) } \\
\text { Tianjin YMCA(1895) in Dongma Rd } \\
\text { Taiyuan YMCA(1915) } \\
\text { Guangzhou YMCA(1907) } \\
\text { Hankou YMCA(1912), } \\
\text { Yantai YMCA(1903) } \\
\text { Hong Kong YMCA(1901), } \\
\text { Guangzhou YMCA(1907) Reconstruction } \\
\text { Hangzhou YMCA(1914) } \\
\text { Suzhou YMCA(1919) } \\
\text { Xi'an YMCA(1914), } \\
\text { Zhoucun YMCA(1914), } \\
\text { Hangzhou YMCA(1914) Reconstruction }\end{array}$ \\
\hline Struggling & $\begin{array}{l}1924 \\
1925 \\
1926\end{array}$ & $\begin{array}{l}\text { Baoding YMCA(1913) } \\
\text { Taishan YMCA(1911), } \\
\text { Chengdu YMCA(1910) Reconstruction } \\
\text { Jinan YMCA(1913), } \\
\text { Nanjing YMCA(1912), Ningbo } \\
\text { YMCA(1919), Changsha YMCA(1913) } \\
\text { Nanchang YMCA(1916), } \\
\text { Xiamen YMCA(1912) } \\
\text { Taiyuan YMCA(1915) Reconstruction } \\
\text { Hankou YMCA(1912) Reconstruction }\end{array}$ \\
\hline Reviving & $\begin{array}{l}1930 \\
1933 \\
1935 \\
\end{array}$ & $\begin{array}{l}\text { Yantai YMCA(1903) Reconstruction } \\
\text { Shanghai YMCA(1900) in Baxian Qiao } \\
\text { Kunming YMCA(1912) }\end{array}$ \\
\hline
\end{tabular}




\section{CONCLUSION}

As the first purpose-built YMCA club with gymnasium in China, Shanghai YMCA Sichuan Rd Club inherited American YMCA Buildings, created the Chinese YMCA characteristics and spread them all over China. During this process, western sport was transformed from the entertainment for the upper class to the public activities for everyone, extending the influence of sport movement. Several upcoming China National Sport Games organized by China YMCA and the attendance at Far East Games after 1912 led by China YMCA indicated its remarkable contribution to China early sport movement.

The second period (of China sport movement) is from 1909 to 1919, when sport developed rapidly...... At that time, Dr. M. T. Exner truly made a great contribution on Chinese Health Study and attracted the attention of other institutes. In the latter half, the sport institutes all over China cooperated and in 1910 Nanjing, when Nanyang industrial exhibition was opened, with the lead of Dr. Exner, the first Chinese Sport Games was held and 158 people attended. [2]

On the other hand, with the success of Shanghai YMCA Sichuan Rd Club and the popularity of physical education, the China YMCA principle of Deyu (morality), Zhiyu (intelligence) and Tiyu (sport) [3] was finally put into practice. (Fig. 25) This advanced western education system led to the evolution and improvement of Chinese education system, especially physical education.

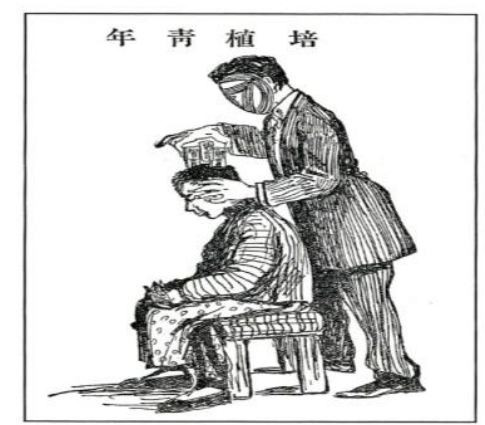

Fig. 25. Youth education principle of China YMCA [8].

\section{ACKNOWLEDGEMENT}

Firstly, I appreciate the support of all of my colleagues from the office 220 of Urban Design Institute of Tsinghua University. The good research environment gives a smooth space for thinking. Secondly, I would like to thank my parents for the support of my PhD study. Thirdly, I appreciate the support of the Shanghai Puguang High School and Shanghai City Archives. Finally, I'm grateful for the revisions suggested by my tutor, Professor ZHU Wenyi.

\section{REFERENCES}

[1] C. Eric, The Temple of Perfection: A History of the Gym, Reaktion Books, p. 7-105, 2015.

[2] SONG Ruhai, "The contribution of YMCAS to sport in China," Fifty-Anniversaries of YMCA in China, pp. 59-60, 1935.

[3] Z. W. Zhang The Struggle of Christianization and SecularizationStudy of Shanghai YMCAs 1909-1922, National Taiwan University Press, pp. 96-234, 2010.

[4] L. Paula, Manhood Factories: YMCA Architecture and the Making of Modern Urban Culture, U of Minnesota Press, pp. 23-151, 2010.

[5] S. X. Bao, "Shanghai YMCA has the first swimming pool in china," no. 3, p. 4, 1915.

[6] W. Arnold. Twentieth Century Impressions of Hong Kong, Shanghai, and other Treaty Ports of China: Their History, People, Commerce, Industries, and Resources, Lloyds Greater Britain publishing Company. vol. 1, p. 632, 1908 .

[7] F. H. Zhang and Y. N. Li, "A study on Tsinghua west stadium," Chinese Early Architectures' Study and Preservation, Beijing: Tsinghua University Press, no. 6, pp. 379-380, 2008.

[8] Youth Education Principle of China YMCA, Shanghai Qing Nian (Shanghai Youth), vol. 18, no. 9, p. 3, 1919

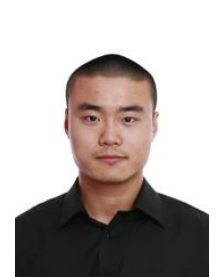

Liu Pinghao was born in Wuhu, Anhui province, P. R.China in 1988. He got his bachelor of architecture, Tsinghua University, Beijing, China in 2010. He has been a master of architecture, Tsinghua University in Beijing China since 2012. His major field is architecture design and urban design

He worked in KPF Shanghai Office as an intern in 2010 and Shanghai Xian Dai Architectural Design Group in 2011 as an intern. Now he works as a PhD Candidate in School of Architecture, Tsinghua University. His current research interests include architecture and urban design, theory of architecture.

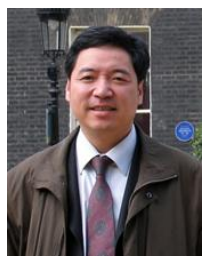

Zhu Wenyi was born in Chengdu, Sichuan province, in 1963. He is a $\mathrm{PhD}$ of architecture in Tsinghua University, Beijing, China in 1993. His major field is architecture design and urban design.

He has worked as faculty and architect in School of Architecture, Tsinghua University from 1993. He has published 18 books and 210 papers, also finished about 80 architectural and urban design projects

including practices.

Prof. Zhu Wenyi is the chair of academic committee and director of Urban design institute, School of Architecture, Tsinghua University, Beijing P.R.China. 